\title{
Hubungan Kadar Plumbum (Pb) Dalam Darah dengan Prestasi Belajar Pada Anak Sekolah di SDN Grinting 01 Kecamatan Bulakamba Kabupaten Brebes
}

\author{
M. Romli ${ }^{1}$, Suhartono ${ }^{2}$, Onny Setiani ${ }^{2}$ \\ ${ }^{1}$ Dinas Kesehatan Kabupaten Batang Hari Jambi \\ ${ }^{2}$ Program Magister Kesehatan Lingkungan Fakultas Kesehatan Masyarakat, Universitas Diponegoro \\ Info Artikel : Diterima Juni 2016 ; Disetujui September 2016 ; Publikasi Oktober 2016
}

\begin{abstract}
Title : Association between Blood Lead Level and Learning Achievement on the Students at Grinting 01 Elementary School, Bulakamba District, Brebes Regency

Background: Plumbum (Pb) is a highly poisonous heavy metal, especially for the children. Pb enters the human body through the respiratory and gastrointestinal tract, and also skin. The aim of this study was to determine the correlation between blood lead level and the learning achievement on the students in Grinting 01 Elementary School, Bulakamba District, Brebes Regency.

Methods: This study was an observational research using cross sectional design. The subjects were 51 students. The data were collected using interview and observational field. The exposure of blood lead level was measured by detecting Pb content in blood according to the result of laboratory test by ASS method (Atomic absorbance spectrometer), and the learning achievement was measured using MST (Middle Semester Test) score of the students. Univariate analysis and bivariate analysis (Chi-Square) were used to analyze the data.

Results: The result of bivariate test indicated that there was no correlation between blood lead level and learning achievement with $p>0.05$. For in the ehole samples, the blood lead level were more than Normal standard of CDC $(\geq 5 \mu \mathrm{g} / \mathrm{dL})$ with the highest Pb in blood is $48.39 \mu \mathrm{g} / \mathrm{dL}$ and the lowest is $11.06 \mu \mathrm{g} / \mathrm{dL}$.

Conclusion: In conclusion, $\mathrm{Pb}$ concentration - in blood on the children does not influence the learning achievement directly.
\end{abstract}

Keywords: blood lead level; learning achievement; Elementary student

\section{PENDAHULUAN}

Timbal adalah logam berat yang sangat beracun terutama terhadap anak-anak. Masuknya timbal kedalam tubuh melalui saluran pernafasan dan saluran percernaan serta kulit. ${ }^{1}$ Menurut WHO, timbal bisa masuk dalam lingkungan dan tubuh manusia dari berbagai macam sumber seperti, diantaranya: mainan anak- anak, udara, air minum yang mengalir dalam pipa mengandung $\mathrm{Pb}$, baterai, cat, krayon, kosmetik, tinta cetak, solder, pemberat pancing, peluru senapan angin, furniture, pernis, tanah dan sebagainya. beberapa jenis kosmetik dan obat tradisional dan juga berbagai sumber lainnya, seperti dalam pestisida dan herbisida golongan organoposfat serta pada alat-alat dapur yang digunakan untuk memasak setiap hari. ${ }^{2,3}$ Timbal dapat masuk ke dalam tubuh manusia melalui saluran pernapasan (inhalasi), saluran pencernaan (oral) dan kulit (dermal) seperti ketika manusia bernapas (menghirup), makan, menelan, terserap dikulit atau melalui plasenta ibu hamil yang menderita keracunan timbal serta meminum zat apa saja yang mengandung timbal. ${ }^{4}$

Anak dapat menyerap hingga 50\% timbal yang masuk ke dalam tubuh, sedangkan orang dewasa hanya menyerap $10-15 \% .^{5}$ Keracunan $\mathrm{Pb}$ pada anak akan menyebabkan penurunan kecerdasan dan perubahan perilaku pada anak. Timbal juga bisa menyebabkan penyakit serius bagi kesehatan anakanak, khususnya pada sistem syaraf terutama menurunnya perkembangan otak dan IQ pada anakanak, encephalopati, ganguan kardiovaskuler, hyperactive, susah dalam belajar, masalah dalam bersikap seperti kurang peduli dan aggressive, rusak 
alat pendengaran

dan

pertumbuhannya. ${ }^{6,7}$

Kadar $\mathrm{Pb} 2 \mu \mathrm{g}$ adalah batas aman maksimum dalam darah. Peningkatan hingga $10 \mu \mathrm{g} / \mathrm{dl}$ akan berisiko menurunnya kecerdasan, penurunan konsentrasi dan disertai hiperaktifitas/ ADHD, kenakalan dan perilaku kriminal. ${ }^{8}$ Pada kandungan 10$30 \mu \mathrm{g} / \mathrm{dl}$ dalam darah, setiap kenaikan kandungan $\mathrm{Pb}$ $10 \mu \mathrm{g} / \mathrm{dl}$ diperkirakan akan menurunkan skor IQ 2-3 poin dan setiap kenaikan $1 \mu \mathrm{g} / \mathrm{dl}$ akan menurunkan 0,5 skor kemampuan aritmatika dan membaca. ${ }^{9}$

Hasil penelitian yang dilakukan oleh Shiek. B. Y di Taibah, Arab Saudi terhadap 167 siswa menunjukan $85 \%$ responden memiliki konsentrasi $\mathrm{Pb}>10 \mu \mathrm{g} / \mathrm{dl}$ dalam darah dan $16,8 \%$ responden memiliki $<10 \mu \mathrm{g} / \mathrm{dl}$ dan hasilnya menunjukan adanya penurunan IQ dan performa kerja. $^{10}$ Penelitian yang dilakukan oleh Haryanto di Jakarta pada anak sekolah dasar kelas III dan IV dari 203 anak ditemukan rata-rata kadar $\mathrm{Pb}$ dalam darah 4,2 $\mu \mathrm{g} / \mathrm{dL}$ dan proporsi anak dengan kadar $\mathrm{Pb}$ dalam darah $\geq 10 \mu \mathrm{g} / \mathrm{dL}$ sebesar $1,3 \% .{ }^{11}$ Hasil Penelitian yang dilakukan oleh Puji Lestari, dkk di Kota Bandung adalah dari 400 siswa tersebut $34,5 \%$ memiliki konsentrasi timbal dalam darah $<10$ $\mu \mathrm{g} / \mathrm{dl}$ dan $65,5 \%$ memiliki konsentrasi timbal dalam darah $>10 \mu \mathrm{g} / \mathrm{dl}$. Rata rata tertinggi ditemukan pada kelompok anak-anak yang berusia 11 tahun yaitu 17,0 $\mu \mathrm{g} / \mathrm{dl}$ dan kelompok usia 10 tahun sebesar 14,75 $\mu \mathrm{g} / \mathrm{dl}$, yang terendah adalah pada kelompok usia 7 tahun yaitu $12,19 \mu \mathrm{g} / \mathrm{dl} .{ }^{12}$

Sementara itu hasil penelitian Khayan menunjukkan bahwa anak sekolah di Kota Pontianak memiliki kadar $\mathrm{Pb}$ dalam Darahnya yang melebihi Nilai Ambang Batas (NAB) adalah sebanyak 43 siswa $(68,25 \%)$ dari 63 sampel yang diteliti. ${ }^{13}$

Faktor lain yang bisa menyebabkan kadar timbal $(\mathrm{Pb})$ dalam darah adalah akibat paparan kimia lain seperti adanya pestisida. ${ }^{14}$ Logam berat yang kemungkinan tercemar di Desa Grinting adalah timbal $(\mathrm{Pb})$, yang diyakini bersumber dari makanan laut dan juga sayuran yang bersumber dari penggunaan bahan kimia dalam meningkatkan produktifitas pertanian seperti penggunaan pestisida yang berlebihan.

Penelitian tentang prestasi belajar siswa pernah dilakukan oleh Yunike tahun 2015 di SD Negeri 01 Dukuhlo Kecamatan Bulakamba Kabupaten Brebes. Hasil penelitian tersebut diketahui bahwa rata-rata prestasi belajar siswa kelas 4 SD Negeri Dukuhlo Kecamatan Bulakamba untuk mata pelajaran bahasa Indonesia sebesar 69,68 , matematika dengan rata-rata 67,83 , IPA dengan rata rata 71,38 dan IPS dengan rata-rata $74,74 . .^{15}$

Sehubungan dengan kenyataan tersebut maka dapat dirumuskan suatu pertanyaan penelitian sebagai berikut: "Adakah hubungan antar kadar timbal $(\mathrm{Pb})$ dalam darah dengan prestasi belajar pada anak di Sekolah Negeri Grinting 01 Kecamatan Bulakamba Kabupaten Brebes?"

\section{METODE PENELITIAN}

Penelitian ini adalah penelitian observasional dengan pendekatan cross sectional. Subyek penelitian adalah anak usia sekolah yang berumur 9-11 tahun di Sekolah Dasar Negeri 01 Grinting Kabupaten Brebes. Kriteria pemilihan subyek menggunakan kriteria inklusi yaitu anak sekolah dalam keadaan sehat, bersedia ikut dalam penelitian. Subyek yang bersedia mengikuti jalannya penelitian menandatangani informed consent yang diwakili oleh walinya. ${ }^{16}$ Variabel penelitian terdiri dari kadar timbal dalam darah. Pemeriksaan kadar Pemeriksaan kadar $\mathrm{Pb}$ dalam darah menggunakan metode AAS (Atomic Absobance Spectrometer) dan metode pemeriksaan eksresi yodium urine menggunakan Acid Digestion dengan larutan ammonium persulfate yang dilakukan oleh petugas laboratorium GAKY Fakultas Kedokteran Undip, Semarang. Untuk kepentingan analisis data kadar timbal dalam darah dikategorikan berdasarkan nilai rata-rata. "Tinggi" bila kadar timbal dalam darah anak lebih dari nilai rata-rata dan "rendah" bila kadar timbal dalam darah anak kurang dari atau sama dengan nilai rata-rata. Penggunan cut off nilai rata-rata karena semua kadar timbal darah anak telah melebihi nilai ambang batas yang telah direkomendasikan CDC sebesar $5 \mu \mathrm{g} / \mathrm{dL} .{ }^{17}$ Analisis statistik yang digunakan uji korelasi Chi-Square untuk melihat hubungan antar variabel.

Populasi pada penelitian ini adalah siswa-siswi sekolah dasar Kelas IV di SDN 01 Grinting Kecamatan Bulakamba Kabupaten Brebes dan sampel yang akan diteliti adalah berjumlah 51 siswa. Variabel bebas dalam penelitian ini adalah kadar $\mathrm{Pb}$ dalam darah dan variabel terikatnya prestasi belajar yaitu dengan mengkategorikan nilai rata-rata tiap mata pelajaran Bahasa Indonesia, Matematika dan Ilmu Pengetahuan Alam. Untuk nilai mata pelajaran Bahasa Indonesia ditetapkan batas KKM (kriteria ketuntasan minimal) adalah 70 , sedangkan untuk nilai mata pelajaran Matematika dan Ilmu Pengetahuan Alam ditetapkan batas KKM adalah 60. Data di analisis dengan uji chis-square pada alfa 0,05 .

\section{HASIL DAN PEMBAHASAN}

Penelitian ini bertujuan untuk untuk menganalisis hubungan kadar timbal $(\mathrm{Pb})$ dalam darah dengan prestasi belajar pada anak di Sekolah Dasar Negeri Grinting 01 Kecamatan Bulakamba Kabupaten Brebes.

\section{Kadar Pb dalam darah}

Dari hasil penelitian diketahui kadar timbal $(\mathrm{Pb})$ dalam darah yang terdeteksi dari hasil pemeriksaan Laboratorium dengan rata-rata sebesar $31,71 \mu \mathrm{g} / \mathrm{dL}$ dan tertinggi 48,39 $\mu \mathrm{g} / \mathrm{dL}$ serta terendah 11,06 $\mu \mathrm{g} / \mathrm{dL}$.

Keracunan yang ditimbulkan oleh perseyawaan logam berat $\mathrm{Pb}$ dapat terjadi karena masuknya persenyawaan logam tersebut kedalam tubuh. Proses masuknya timbal $(\mathrm{Pb})$ ke dalam tubuh manusia melalui saluran pernapasan (inhalasi), saluran 
pencernaan (oral) dan kulit (dermal) seperti ketika manusia bernapas (menghirup), makan, menelan, terserap dikulit atau melalui plasenta ibu hamil yang menderita keracunan timbal serta meminum zat apa saja yang mengandung timbal. ${ }^{4}$ Senyawa $\mathrm{Pb}$ organik relatif lebih mudah untuk diserap tubuh melalui selaput lendir atau lapisan kulit, bila dibandingkan senyawa-senyawa $\mathrm{Pb}$ anorganik.

\section{Pengukuran Kadar Timbal}

Berdasarkan tabel 1 dapat diketahui bahwa responden yang memiliki kadar $\mathrm{Pb}$ dalam darah tinggi sebanyak 23 responden (44,2\%) sedangkan responden yang memiliki kadar $\mathrm{Pb}$ dalam darah rendah sebanyak 29 responden $(55,8 \%)$, dengan rata-rata $31,71 \mu \mathrm{g} / \mathrm{dL}$.

Hasil analisis deskripitif pada gambar 2 kadar timbal $(\mathrm{Pb})$ dalam darah yang terdeteksi dari hasil pemeriksaan Laboratorium dengan rata-rata sebesar $31,71 \mu \mathrm{g} / \mathrm{dL}$ dan terginggi $48,39 \mu \mathrm{g} / \mathrm{dL}$ serta terendah $11,06 \mu \mathrm{g} / \mathrm{dl}$. Pada penelitian ini menunjukan bahwa dari 51 orang $(100 \%)$ ditemukan kadar $\mathrm{Pb}$ dalam darah anak tidak normal dan telah melewati ambang batas berdasarkan nilai rujukan CDC sebesar $5 \mu \mathrm{g} / \mathrm{dL}$, dimana hasil penelitian ini mendapatkan nilai rata-rata $31,71 \mu \mathrm{g} / \mathrm{dL}$. Kadar timbal $(\mathrm{Pb})$ yang diperoleh dari penelitian ini jauh lebih tinggi dibandingkan dengan penelitian lain.

Hasil penelitian ini berbeda dengan penelitian yang dilakukan oleh Lanphear menunjukkan untuk setiap kenaikan $1 \mathrm{pg} / \mathrm{dL}$ konsentrasi timbal dalam darah, ada penurunan 0,7 poin dalam rata-rata skor aritmatika dan membaca, 0,1 poin penurunan dalam skor rata-rata pada ukuran penalaran nonverbal, dan 0,5 poin penurunan dalam skor rata-rata pada ukuran memori jangka pendek. ${ }^{9}$

Penelitian yang dilakukan oleh Shiek. B. Y di Taibah tahun 2010, Arab Saudi terhadap 167 siswa menunjukan $85 \%$ responden memiliki konsentrasi $\mathrm{Pb}$ $>10 \mu \mathrm{g} / \mathrm{dl}$ dalam darah dan $16,8 \%$ responden memiliki $<10 \mu \mathrm{g} / \mathrm{dl}$ dan hasilnya menunjukan ada hubungan kadar $\mathrm{Pb}$ dalam darah dengan penurunan IQ dan performa kerja. ${ }^{10}$

\section{Prestasi Belajar}

Hasil analisis deskripitif pada tabel 2 Variabel Bahasa Indonesia memiliki nilai rata-rata 78,82 , nilai Bahasa Indonesia tertinggi 92,00 dan nilai Bahasa Indonesia terendah 68,00. Proporsi anak dengan nilai kurang dari KKM sebesar (3,9\%). Variabel Matematika memiliki nilai rata-rata 78,07 nilai Matematika tertinggi 89,00 dan nilai Matematika terendah 69,00. Variabel Ilmu Pengetahuan Alam memiliki nilai rata-rata 78,21 nilai Ilmu Pengetahuan Alam tertinggi 87,00 dan nilai Ilmu Pengetahuan Alam terendah 70,00, dan semua nilai anak telah melewati KKM untuk mata pelajaran Matematika dan Ilmu Pengetahuan Alam

\section{Hubungan kadar timbal (Pb) dalam darah dengan prestasi belajar}

Pajanan logam berat timbal $(\mathrm{Pb})$ merupakan masalah kesehatan masyakat. Meskipun jumlah $\mathrm{Pb}$ yang diserap oleh tubuh hanya sedikit, logam ini ternyata menjadi sangat berbahaya. Hal itu disebabkan senyawa-senyawa $\mathrm{Pb}$ dapat memberikan efek racun terhadap banyak fungsi organ yang terdapat dalam tubuh. Pajanan logam berat $\mathrm{Pb}$ dapat menyebabkan gangguan pada anak yang menyebabkan penurunan kecerdasan dan perubahan perilaku pada anak. Timbal juga bisa menyebabkan penyakit serius bagi kesehatan anak-anak, khususnya pada sistem syaraf terutama menurunnya perkembangan otak dan IQ pada anakanak, encephalopati, ganguan kardiovaskuler, hyperactive, susah dalam belajar, masalah dalam bersikap seperti kurang peduli dan aggressive, rusak alat pendengaran dan memperlambat pertumbuhannya. ${ }^{6,7}$

Hasil uji Chi-Square untuk mengetahui hubungan kadar $\mathrm{Pb}$ dalam darah dengan nilai Bahasa Indonesia dapat dilihat pada tabel 3. Berdasarkan tabel 3 dapat diketahui bahwa hasil uji beda proporsi kadar timbal $(\mathrm{Pb})$ dalam darah dengan nilai Bahasa Indonesia diketahui bahwa proporsi responden dengan nilai Bahasa Indonesia kurang pada kelompok kadar $\mathrm{Pb}$ dalam darah tinggi (4,3\%) lebih besar dibandingkan proporsi responden dengan nilai Bahasa Indonesia kurang pada kelompok kadar $\mathrm{Pb}$ rendah $(3,6 \%)$. Hasil uji statistik diperoleh nilai $p>0,05$ $(\mathrm{PR}=1,21,95 \%$ CI $0,80-18,41)$ artinya tidak ada hubungan yang bermakna antara kadar $\mathrm{Pb}$ dalam darah dengan nilai Bahasa Indonesia.

Hasil uji Chi-Square untuk mengetahui hubungan kadar $\mathrm{Pb}$ dalam darah dengan nilai Matematika dapat dilihat pada tabel 4. Berdasarkan tabel 4 dapat diketahui hasil uji beda proporsi kadar timbal $(\mathrm{Pb})$ dalam darah dengan nilai Matematika diketahui bahwa proporsi responden dengan nilai Matematika kurang pada kelompok kadar $\mathrm{Pb}$ dalam darah tinggi $(69,6 \%)$ lebih besar dibandingkan proporsi responden dengan nilai Matematika kurang pada kelompok kadar $\mathrm{Pb}$ rendah (50,0\%). Hasil uji statistik diperoleh nilai $p>0,05(\mathrm{PR}=1,39,95 \% \mathrm{CI}$ 0,88-2,20) artinya tidak ada hubungan yang bermakna antara kadar $\mathrm{Pb}$ dalam darah dengan nilai Matematika.

Hasil uji Chi-Square untuk mengetahui hubungan kadar $\mathrm{Pb}$ dalam darah dengan nilai Ilmu Pengetahuan Alam dapat dilihat pada tabel 5 . Berdasarkan tabel 5, hasil uji beda proporsi kadar timbal $(\mathrm{Pb})$ dalam darah dengan nilai Ilmu Pengetahuan Alam diketahui bahwa proporsi responden dengan nilai Ilmu Pengetahuan Alam kurang pada kelompok kadar $\mathrm{Pb}$ dalam darah tinggi $(52,2 \%)$ lebih besar dibandingkan proporsi responden dengan nilai Ilmu Pengetahuan Alam kurang pada kelompok kadar $\mathrm{Pb}$ rendah (46,4\%). Hasil uji statistik diperoleh nilai $p>0,05(\mathrm{PR}=1,12,95 \%$ CI $0,64-1,96)$ artinya tidak ada hubungan yang bermakna antara 
kadar $\mathrm{Pb}$ dalam darah dengan nilai Ilmu Pengetahuan Alam.

Menurut Tsuyuoka et all dalam Sakkir dkk konsentrasi $1 \mu \mathrm{g} / \mathrm{m}^{3}$ timbal yang berada di udara, akan berdampak pada peningkatan kadar timbal dalam darah antara 2,5-5,3 $\mu \mathrm{g} / \mathrm{dl}$. Apabila telah terakumulasi hingga $10 \mu \mathrm{g} / \mathrm{dl}$ pada seorang anak, maka poin IQ-nya cenderung menurun 2,5 poin, bahkan bisa kehilangan sampai empat poin IQ pada usia tujuh tahun. ${ }^{18}$

Distribusi Frekuensi Karakteristik Subyek Penelitian disajikan dalam tabel 3.

Tabel .1 Hasil Pemeriksaan Kadar Timbal Dalam Darah

\begin{tabular}{clcc}
\hline No & \multicolumn{1}{c}{ Kadar Pb Dalam Darah } & Jumlah & $\%$ \\
\hline 1 & Tinggi $(>31,52 \mu \mathrm{g} / \mathrm{dL})$ & 23 & 45,1 \\
2 & Rendah $(\leq 31,52 \mu \mathrm{g} / \mathrm{dL})$ & 28 & 54,9 \\
& Rata-rata & & 31,71 \\
\hline & Jumlah & 51 & 100,0 \\
\hline
\end{tabular}

Tabel 2. Hasil deskritif variabel penelitian $(n=51)$

\begin{tabular}{|c|c|c|c|c|c|c|}
\hline Variabel & Mean & Median & Min & Max & SD & $\mathbf{f}(\%)$ \\
\hline $\begin{array}{l}\text { Kadar } \mathrm{Pb} \text { dalam darah } \\
(\mu \mathrm{g} / \mathrm{dL})\end{array}$ & 31,71 & 30,92 & 11,06 & 48,39 & 7,83 & \\
\hline Bahasa Indonesia & 78,82 & 78,71 & 68,00 & 92,00 & 5,60 & \\
\hline Matematika & 78,07 & 77,00 & 69,00 & 89,00 & 5,38 & \\
\hline Ilmu Pengetahuan Alam & 78,21 & 79,00 & 70.00 & 87,00 & 4,20 & \\
\hline $\begin{array}{l}\text { Kadar } \mathrm{Pb} \text { dalam darah } \\
(31,71 \mu \mathrm{g} / \mathrm{dL})\end{array}$ & & & & & & $23(45,1)$ \\
\hline $\begin{array}{l}\text { Bahasa Indonesia } \\
(<70 \text { Nilai KKM) }\end{array}$ & & & & & & $2(3,9)$ \\
\hline $\begin{array}{l}\text { Matematika } \\
(<60 \text { Nilai KKM) }\end{array}$ & & & & & & $51(100)$ \\
\hline $\begin{array}{l}\text { Ilmu Pengetahuan Alam } \\
(<60 \text { Nilai KKM) }\end{array}$ & & & & & & $51(1000$ \\
\hline
\end{tabular}

Tabel 3. Hasil uji beda proporsi nilai Bahasa Indonesia

\begin{tabular}{|c|c|c|c|c|}
\hline \multirow{2}{*}{$\begin{array}{c}\text { Variabel } \\
\text { (Kadar } \mathrm{Pb} \text { dalam darah) }\end{array}$} & \multicolumn{2}{|c|}{ Bahasa Indonesia } & \multirow{2}{*}{ PR (CI) } & \multirow[b]{2}{*}{ Nilai- $p$} \\
\hline & Kurang & Baik & & \\
\hline 'Tinggi' $>31,71 \mu \mathrm{g} / \mathrm{dL}(\mathrm{n}=23)$ & $1(4,3 \%)$ & $22(95,7 \%)$ & 1.21 & \\
\hline 'Rendah' $\leq 31,71 \mu \mathrm{g} / \mathrm{dL} \quad(\mathrm{n}=28)$ & $1(3,6 \%)$ & $27(96,4 \%)$ & $(0,80-18,41)$ & 1,000 \\
\hline
\end{tabular}

Keterangan: ${ }^{a}$ Uji Chi-Square,${ }^{*}$ Significant Nilai $p<0,05$

Tabel 4. Hasil uji beda proporsi nilai Rata-rata KKM Matematika

\begin{tabular}{|c|c|c|c|c|}
\hline \multirow{2}{*}{$\begin{array}{c}\text { Variabel } \\
\text { (Kadar } \mathrm{Pb} \text { dalam darah) }\end{array}$} & \multicolumn{2}{|c|}{ Matematika } & \multirow[b]{2}{*}{ PR (CI) } & \multirow[b]{2}{*}{ Nilai- $p$} \\
\hline & Kurang & Baik & & \\
\hline 'Tinggi' $>31,71 \mu \mathrm{g} / \mathrm{dL}(\mathrm{n}=23)$ & $16(69,6)$ & $7(30,4)$ & 1,39 & \\
\hline 'Rendah' $\leq 31,71 \mu \mathrm{g} / \mathrm{dL}(\mathrm{n}=28)$ & $14(50,0)$ & $14(50,0)$ & $(0,88-2,20)$ & 0,260 \\
\hline
\end{tabular}

Keterangan: ${ }^{a}$ Uji Chi-Square, ${ }^{*}$ Significant Nilai $p<0,05$

Tabel 5. Hasil uji beda proporsi nilai Rata-rata KKM Ilmu Pengetahuan Alam

\begin{tabular}{|c|c|c|c|c|}
\hline \multirow{2}{*}{$\begin{array}{c}\text { Variabel } \\
\text { (Kadar } \mathrm{Pb} \text { dalam darah) }\end{array}$} & \multicolumn{2}{|c|}{ IPA } & \multirow{2}{*}{ PR (CI) } & \multirow{2}{*}{ Nilai- $p$} \\
\hline & Kurang & Baik & & \\
\hline 'Tinggi' $>31,71 \mu \mathrm{g} / \mathrm{dL}(\mathrm{n}=23)$ & $12(52,2 \%)$ & $11(47,8 \%)$ & 1.12 & \\
\hline 'Rendah' $\leq 31,71 \mu \mathrm{g} / \mathrm{dL} \quad(\mathrm{n}=28)$ & $13(46,4 \%)$ & $15(53,6 \%)$ & $(0,64-1,96)$ & 0,899 \\
\hline
\end{tabular}

Keterangan: ${ }^{\text {a } U j i ~ C h i-S q u a r e, ~}{ }^{*}$ Significant Nilai $p<0,05$

Hasil di lokasi penelitian tidak ditemukan adanya hubungan kadar $\mathrm{Pb}$ dalam darah dengan prestasi belajar, karena kemungkinan paparan $\mathrm{Pb}$ belum merusak jaringan susunan saraf pusat. Hal ini serupa dengan penelitian yang dilakukan oleh Lestari, dkk tahun 2011 memiliki hubungan terbalik terhadap point IQ. ${ }^{14}$

Selain dari faktor tersebut diatas, faktor lain yang berpotensi menyebabkan tidak ditemukan adanya hubungan kadar $\mathrm{Pb}$ dalam darah dengan prestasi belajar adalah pestisida. ${ }^{19}$ Berdasarkan hasil observasi 
di lokasi penelitian ditemukan beberapa masyarakat menyimpan hasil panen bawang merah di sekitar rumah, tentunya ini sangat berpotensi bagi anak-anak untuk bermain di sekitar tempat penyimpanan bawang merah, sehingga anak bisa terpapar dari residu pestisida yang ada pada bawang merah.

Penelitian yang dilakukan Hartono E. tahun 2014 menemukan ada hubungan riwawat pajanan pestisida dengan prestasi belajar pada murid SD di daerah pertanian Kabupaten Brebes dengan nilai $\mathrm{p}=0,009$. Jadi dapat dikatakan bahwa pajanan pestisida yang tinggi beresiko pada terjadinya penurunan prestasi belajar. $^{20}$

Penelitian oleh Maryse F. B tahun 2011 tentang hubungan paparan pestisida organofosfat dan IQ anak 7 tahun di California, USA ada hubungan antara paparan pralahir pestisida organofosfat dengan buruknya perkembangan IQ anak usia 7 tahun. $^{21}$ Selain dari pajanan pestisida prestasi belajar siswa dapat dipengaruhi oleh minat, motivasi belajar, lingkungan, fasilitas mengajar dan lain sebagainya ikut mempengaruhi prestasi. Hasil pengamatan peneliti menemukan bahwa fasilitas sekolah sudah dapat disebut baik. Fasilitas yang baik ini diharapkan dapat berkontribusi secara tidak langsung terhadap peningkatan prestasi belajar siswa. Menurut Slameto tahun 2005 faktor-faktor yang mempengaruhi prestasi belajar Seperti minat, motivasi, kualitas guru, metode mengajar, lingkungan, fasilitas mengajar dan lain sebagainya ikut mempengaruhi prestasi belajar. Namun faktor kecukupan gizi seseorang dapat mempengaruhi prestasi belajar siswa. ${ }^{18}$

Hasil penelitian kondisi responden yang secara umum menunjukkan sama/homogen, dengan demikian sulit untuk diketahui faktor manakah yang menjadi faktor resiko yang berpengaruh terhadap prestasi belajar. Prestasi belajar yang diukur dengan nilai UTS (ujian tengah semester) siswa juga tidak serta merta dapat digunakan untuk mengetahui kemampuan kognitif siswa. Faktor penilaian guru secara subjektif dan saling mencontek antar siswa belum bisa dikendalikan dalam penelitian ini.

\section{SIMPULAN}

Penelitian ini menemukan kadar timbal $(\mathrm{Pb})$ dalam darah pada anak sekolah di SDN Grinting 01 Kecamatan Bulakamba Kabupaten Brebes semuanya sudah melebihi ambang batas normal yang ditentukan oleh standar CDC yakni sebesar $5 \mu \mathrm{g} / \mathrm{dL}$ (rata-rata $31,71 \mu \mathrm{g} / \mathrm{dl}$ ), yang dapat membahayakan kesehatan anak sekolah. Hasil analisis statistik menunjukkan tidak ada hubungan bermakna antara kadar timbal $\mathrm{Pb})$ dalam darah dengan nilai pelajaran Bahasa Indonesia, Matematika dan Ilmu Pengetahuan Alam pada anak sekolah di SDN Grinting 01 Kecamatan Bulakamba Kabupaten Brebes.

Kepala para petani disarankan agar tidak menyimpan hasil pertaniannya di dalam rumah seperti bawang merah, supaya anak-anak terhindar dari paparan residu pestisida, serta agar mencuci sayuran atau lalapan mentah terlebih dahulu sebelum dikonsumsi.

\section{DAFTAR PUSTAKA}

1. WHO. Exposure to lead: A major public health concern. preventing disease through healthy environments. Public health and environment. 2010. Diakses dari: http://www.who.int/ipcs/ features/lead.pdf.

2. WHO. Issues brief series: lead. Geneva: WHO HECA (World Health Organization Healthy Environments for Children Alliance), 2012.

3. Jones AL, Emerging aspects of assessing lead poisoning in Childhood, Emerging Health Threats Journal 2009, 2: p. 2-9.

4. Denny A. Deteksi pencemaran timah hitam $(\mathrm{Pb})$ dalam darah masyarakat terpajan timbal (plumbum). Jurnal Kesehatan Lingkungan Juli 2005: 2(1): p. 67-8.

5. Albalak R, Noonan G, Buchanan S, Flanders WD, Gotway-Crawford C, Kim D, et al. Blood lead levels and risk factors for lead poisoning among children in Jakarta, Indonesia. The Science of the Total Environment 1 Januari 2003; 301 (1-3): p. 75- 85.

6. Meyer PA, Michael MA, Henry F. A global approach to childhood lead poisoning prevention. International Journal Hygiene Environmental Health August 2003; 206: p. 363-9.

7. Darmono. Lingkungan hidup dan pencemaran. Jakarta: Universitas Indonesia Press, 2001.

8. Miodovnik MD, Environmental Neurotoxicants and Developing Brain, Mount Sinai Journal of Medicine, 2011, 78: p. 58-77.

9. Lanphear et.all, Low-Level Environmental Lead Exposure and Children's Intellectual Function: An International Pooled Analysis, Environmental Health Perspectives 2005,113: p. 894-9.

10. Shiek, et. al. 2010. Measurement Of Blood Lead Levels Among Medical Students In Faculty Of Medicine Taibah University And Their Effects On Intelligent Quotients And Study Performance Rates. International Journal Of Academic Research (Online), (www.mdpi.com/journal/ijerph).

11. Haryanto B. Blood-lead monitoring exposure to leaded-gasoline among school children in Jakarta, Indonesia 2005. Jurnal Kesehatan Masyarakat Nasional Apri 2007: 1(5); p. 214-8.

12. Lestari, P. 2005. Faktor-faktor yang Berpengaruh Terhadap Kadar Timbal Dalam Darah AnakAnak Sekolah Dasar di Kota Bandung. Journal Indonesian Lead Information Center, (Online), (http://www.hamline.edu/apakabar/basisdata/201 $1 / 17 / 02)$

13. Kayan. Tingkat pencemaran timbal $(\mathrm{Pb})$ dalam darah dengan prestasi belajar anak SD di Kota 
Pontianak. Jurnal Ilmu Kesehatan. Juli 2012. Vol XIII (2): hal. 142-152.

14. La Rocca C, Mantovani A. From environmental to food: the case of PCB. Ann Ist Super Sanita 2006, 42(4): p. 410-6.

15. Yunike V. Hubungan paparan pestisida dengan prestasi belajar siswa SD di SD Negeri 1 Dukuhlo Kecamatan Bulakamba Kabupaten Brebes (Tesis). Universitas Diponegoro; 2015.

16. Sastroasmoro S, Ismael S. Dasar-dasar metodologi penelitian klinis. Edisi 4. Jakarta: Sagung Seto, 2011.

17. Central for Diseases Control and Prevention (CDC). Blood lead levels in children 2015. ailablefrom:http://www.cdc.gov/nceh/lead acclpp/lead_levels inchildren_fact_sheet.pdf Diakses pada tanggal 31 November 2015
18. Widiowati W, Sastiono A, Jusuf R. Efek tosik logam: pencegahan dan penanggulangan pencemaran. Jogjakarta: Andy Offset, 2008.

19. Diamanti-Kandarikis E, Bourguignon J, Giudice C Linda, Hauser R, Prins S G, Soto M Ana, et al. Endocrine-disrupting chemicals. An endocrine society scientific statement. USA: The Endocrine Society; 2009.

20. Hartono E, Hubungan riwayat pananan pestisida dengan prestasi belajar(Studi pada murid SD di daerah pertanian Kabupaten Brebes): (Tesis), 2014.

21. Bouchard, M. F. Prenatal exposure to organophosphate pesticides and IQ in 7-year-old children. Environmental Health Perspectives, 119,1189-1195.2011. 